\section{Lick volume determined by food schedules in rats*}

\author{
ARTHUR S. WILSON and JOSEPH J. BARBORIAK \\ Veterans Administration Center, Wood \\ and Departments of Psychiatry and Pharmacology \\ Marquette School of Medicine, Milwaukee, Wis. 53193
}

The number of licks and fluid consumed were recorded separately for 10 rats during a 7-day adjustment period followed by a 33-day period during which the animals were fed for only $2 \mathrm{~h}$ each day. Significant differences in the number of licks per milliliter of water consumed between food and no-food periods appeared after the first experimental week. There was a significant decrease in lick rate from the first to the second hour of each feeding period and also from the feeding to the nonfeeding period. Use of a lick count to determine volumes of fluids ingested on different feeding schedules could be misleading.

Drinkometers, devices that detect mouth contacts with drinking spouts, have been used to measure fluid consumption. Examples of their use include determination of drinking rate following water deprivation (Stellar \& Hill, 1952), food-associated drinking (Kissileff, 1969), and temporal characteristics of drinking (Allison \& Castellon, 1970). Some of the studies have indicated that lick volume, i.e., the amount of liquid intake for each lick, was a constant. Subsequently, this constant has been utilized to determine volume of fluid consumed when only lick counts were recorded (Kissileff, 1969). Possible factors that may modify the amount of fluid per lick, such as presence or absence of solid food, have not been considered. The purpose of this study was to investigate the possible interrelationship between lick volume and the presence or absence of solid food.

\section{METHOD}

Ten male Sprague-Dawley rats weighing approximately $225 \mathrm{~g}$ at the start of the experiment served as Ss. Each animal was individually housed in an operant
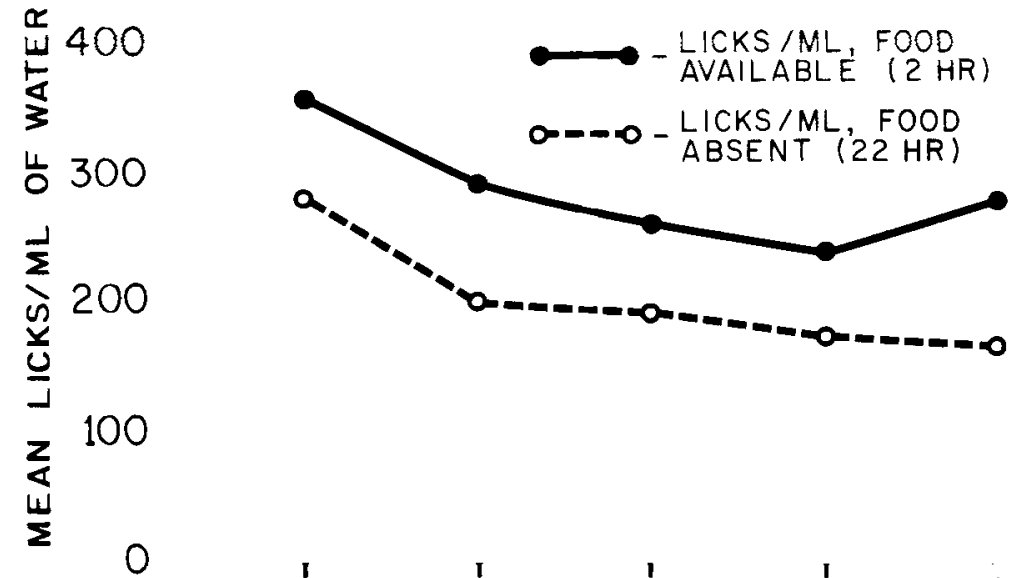

Curves representing the average number of licks per milliliter of water were derived modified by having a food cup installed in one corner. A drinkometer (BRS) was attached to a calibrated drinking tube that had a standard 1/8-in. metal spout. This arrangement enabled recording of licks on cumulative recorders and counters. The volume of water consumed was separately determined. Each animal was placed in the cage and given a 7-day adjustment period of ad lib food and water. The food consisted of ground standard rat diet (Purina Rat Chow). Water and food intake was measured daily. The experiment proper consisted of a 33-day period, during which the animals were fed for only $2 \mathrm{~h}$ each day (9:00-11:00 a.m.). Total fluid consumed and amount of food consumed were recorded at the end of each 2-h feeding period, while the number of licks was recorded hourly during this $2 \cdot h$ period. Total licks and fluid consumed for the remaining $22 \mathrm{~h}$ were also recorded, and animals were weighed weekly.

\section{RESULTS}

from the lick and fluid consumption measures of food and no-food periods and appear in Fig. 1. Each point represents the weekly average for the five experimental intervals. Statistical analysis of these data by $t$ test indicates that no difference is present during the first weekly period, but each subsequent pair of points is significantly different $(p<.01)$.

Calibration during the ad lib period (not shown on this graph) indicated that the Ss averaged $0.0034 \mathrm{ml}$ of water per tongue lap. The average volume per lick during the 2 -h feeding period was $.0036 \mathrm{ml}$, which is not significantly different from that under ad lib conditions. However, the lick volume during the remaining $22 \mathrm{~h}(.0052 \mathrm{ml})$ is significantly higher $(p<.01)$.

Figure 2 presents data on lick rate for each of the $2 \mathrm{~h}$ during the feeding period and an average rate per hour for the remaining $22 \mathrm{~h}$ when food was absent. The greatest frequency of licks is found during the first hour of feeding. There is a significant reduction $(p<.01)$ from the first- to second-hour feeding-period lick rate and also from the feeding to the nonfeeding period.

\section{DISCUSSION}

The amount of water delivered for each tongue lap during the preexperimental period $(0.0034 \mathrm{ml})$ is similar to that previously obtained by others (Stellar \& Hill, 1952) when food is available ad lib. However, the number of licks per milliliter is significantly lower during periods when no food is available than when food is

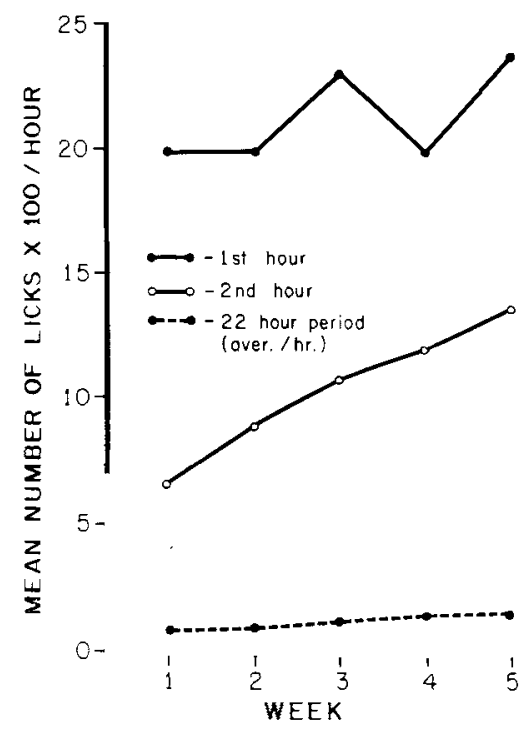

Fig. 2. Mean number of licks per hour during the food and no-food periods.

* The excellent technical assistance of Mr. Philip Duncan is gratefully acknowledged.
Fig. 1. Mean number of licks per $\mathrm{ml}$ of water consumed during the food and no-food periods for the 5 experimental weeks. 
present. This difference became apparent only after the first week of food scheduling. The significant difference in the number of licks needed to consume one milliliter of water when food is present compared to the number of licks when food is absent clearly indicates that lick volume is not a constant. The difference in lick volume generated by the presence or absence of food can probably be related to differences in the frequency of licks under these two conditions. In the presence of food, the rat apparently licks at a rate that prevents the full amount of water from reaching the tongue. Thus, use of a lick count to determine volumes of ingested fluids by rats on different feeding schedules could be misleading. Also, examination of the volume-per-lick data derived from this experiment indicates that an animal's liquid intake can be modified by the presence of solid food.

\section{REFERENCES}

ALlisON, J., \& CASTELLAN, N. J. Temporal characteristics of nutritive drinking in rats and humans. Journal of Comparative \& Physiological Psychology, 1970, 70, 116-125. KISSILEFF, H. R. Food-associated drinking in the rat. Journal of Comparative \& Physiological Psychology, 1969, 67, 284-300. STELLAR, E., \& HILL, J. H. The rat's rate of drinking as a function of water deprivation. Journal of Comparative \& Physiological Psychology, 1952, 45, 96-102.

\section{A note on the effects of chlorpromazine upon ulceration in the rat}

\author{
K. SHEMBERG, P. C. GREEN, and J. GLINER \\ Bowling Green State University, Bowling Green, Ohio 43402
}

Four groups of rats were exposed to a highly ulcerogenic procedure. Three experimental groups were given programmed injections of three different concentrations of chlorpromazine and a control group received physiological saline. All drug concentrations significantly reduced ulceration relative to controls. The lowest concentration proved least effective in this regard, but no simple linear relationship was found between drug concentration and frequency of ulceration. A tentative hypothesis regarding an all-or-none protective function of the drug was suggested, and parameters for future research outlined.

There has been a substantial amount of research aimed at discovering and elaborating the parameters relevant to the production of stress-induced gastric ulcers in the rat (e.g., conflict, Sawrey \& Weisz, 1956; conditioned fear, Mikhail, 1969; and operant control over aversive events, Weiss, 1968). However, there has been little systematic research concerning the effects of drugs on ulcer development, and, more particularly; there has been almost no work on the effects of chlorpromazine as an antiulcerogenic agent. There are suggestions in the literature that this drug, along with other central neurotropic substances, may effectively reduce stress-induced gastric ulceration and that it may be more effective in this regard than some other agents, i.e., morphine, atropine, and others (e.g., Zabrodin, 1965).

The present research represented an initial effort to examine some of the relationships between chlorpromazine and gastric ulceration in the rat in somewhat greater detail than has been reported previously. One specific purpose of this work was to study the effects of chlorpromazine in a highly ulcerogenic stress situation and to test varying concentrations of this drug in order to detect possible protective effects within this paradigm. The second specific goal was to attempt to discover a concentration level of the drug that effectively reduces or totally inhibits ulceration in a highly stressful setting. Thus, drug concentrations covering a wide range were selected and three values within this range were studied. It was predicted that these values would demonstrate a generally negatively related linear function between concentration level and the degree of gastric pathology. DRUG

The drug utilized was chlorpromazine, $25 \mathrm{mg} / \mathrm{cc}$ (Smith, Kline, \& French).

\section{SUBJECTS}

Ss were 109 male Long-Evans hooded rats, $100-115$ days old and weighing between 345 and $370 \mathrm{~g}$ at time of testing. Ss were assigned randomly to one of four conditions in which the stock drug solution was diluted as indicated: $1 / 50$ th $(\mathrm{N}=21)$; $1 / 20$ th $(\mathrm{N}=20) ; 1 / 10$ th $(\mathrm{N}=27) ;$ and saline control $(\mathrm{N}=41)$.

\section{APPARATUS}

Twelve $11.5 \times 11.5 \times 12$ in. Plexiglas boxes served as test cages. The grid floors of these cages were wired so that scrambled electric shock could be delivered simultaneously to all boxes via four Grason-Stadler E1064GS shock generators. All sides of the test cages were covered by black contact paper to provide visual isolation. Shock schedules were programmed via an LVE tape programmer, and stress-rest cycles were controlled by an LVE Multifunction Interval Timer.

\section{PROCEDURE}

The stress-rest schedule involved first food-depriving all animals for $48 \mathrm{~h}$, placing them into the test cages, and exposing them to a 36 -h stress-rest procedure. This consisted of alternating $2 \mathrm{~h}$ of shock (stress) with $2 \mathrm{~h}$ of no shock (rest). Thus, all Ss received a total of $18 \mathrm{~h}$ of stress and $18 \mathrm{~h}$ of rest on a 2 -h alternating schedule. During each 2-h shock period Ss received 120 random presentations of a $2.0-\mathrm{mA}$, 2 -sec footshock. This basic schedule was developed via preliminary research and was shown to be highly ulcerogenic (i.e., $89 \%$ of all pilot Ss ulcerated while no control Ss deprived for the total $84-h$ period showed gastric pathology). The first injection for

Table 1

\begin{tabular}{|c|c|c|c|}
\hline Group & $\mathbf{N}$ & $\begin{array}{l}\text { Number } \\
\text { Ulcerating }\end{array}$ & $\begin{array}{c}\text { Percent } \\
\text { Ulcerating }\end{array}$ \\
\hline $1 / 50$ th & 21 & 12 & 57 \\
\hline $1 / 20$ th & 20 & 3 & 15 \\
\hline $1 / 10$ th & 27 & 6 & 22 \\
\hline Saline & 41 & 35 & 86 \\
\hline
\end{tabular}

